\title{
Toughness properties at multi-layer laser beam welding of high-strength steels
}

\author{
Joerg Volpp ${ }^{1}$ (D) Pär Jonsén ${ }^{1}$ • Anandkumar Ramasamy ${ }^{2}$. Bert Kalfsbeek ${ }^{2}$
}

Received: 29 July 2020 / Accepted: 28 September 2020 / Published online: 8 October 2020

(C) The Author(s) 2020

\begin{abstract}
The material characteristics of high toughness and high strength in steel are usually not available at the same time. However, it would be an advantage if high-strength steels would show high impact toughness also at lower temperatures for applications in critical surroundings. In this paper, an approach of multi-layer welding of high-strength steel is presented in order to increase the weld-metal toughness using wire material in combination with thermal cycle modifications. Promising interlocking microstructures were found after multiple tempering of the previously applied structure at homogeneously distributed material in the weld seam. It was found that short thermal cycles during laser processing lead to insufficient time for carbon diffusion, which leads to remaining ferrite structures in contrast to the prediction of welding transformation diagrams. The additionally applied heating cycles during multi-layer laser welding induce the formation of interlocking microstructures that help to increase the weld seam toughness.
\end{abstract}

Keywords High-strength steel $\cdot$ Narrow-gap multi-layer welding $\cdot$ Laser welding $\cdot$ Weld metal toughness $\cdot$ Interlocking microstructures

\section{Introduction}

High-strength steel (HSS) processing becomes more and more interesting for reducing the weight of parts at comparable strength values, e.g. for ship building [1], building bridges [2], pressure vessel, gas/oil transportation line pipes, and offshore constructions [3-5]. However, typically at higher strength values of the steel grade, the toughness at low working temperatures decreases [6]. This can be a drawback and a possible reason for avoiding the use of the steel in critical environment.

In general, steel grades with high strength values (up to $1100 \mathrm{MPa}$ ) are produced by quenching and tempering processes. Thereby, the material is reheated above austenization

Recommended for publication by Commission IV - Power Beam Processes

Joerg Volpp

jorg.volpp@ltu.se

1 Department of Engineering Sciences and Mathematics, Luleå University of Technology, SE-971 87 Luleå, Sweden

2 Lincoln Electric Europe, 6534 AD Nijmegen, The Netherlands temperature in order to dissolve the carbon in the austenite. Fast cooling (quenching) is usually used to avoid the formation of ferrite and pearlite, which would require a diffusion process. The carbon can remain dissolved, and after cooling, the microstructure mainly transforms into martensite.

During welding of HSS, complex heat treatment is present leading to microstructural changes and variations of strength and toughness values. Typical welding processes include submerged-arc, SAW; gas-metal-arc, GMAW; or laser-archybrid welding, LAHW. Typically, long cooling times are present, e.g. for GMAW [7] or SAW [8], which can induce the diffusion processes that can lead to softening of the welding zone. Laser and laser-assisted processes show comparably short cooling times (e.g. $[9,10])$.

In order to influence the welding results, mainly two optimization routes are investigated, namely process design and alloy modifications. Process design was used in order to tailor the heat input and thereby the joint properties. Designing the gaps was shown to improve the welding process of 30-mmthick steels [11]. Using the hybrid welding approach showed significant advantages regarding processing speed and tailored heat input in depth of the joint [12]. Another approach was developed and patented by Milewski and Sklar [13] to fill a gap with multiple laser passes, called narrow-gap multi-layer 
welding (NGMLW). It was shown that it is possible to weld thick section materials with relatively moderate laser powers [14-17]. In this process, several thermal cycles are applied, affecting the previous structure. It was observed that the fast cooling of the high-strength material after NGMLW leads to the generation of hard martensite, which leads to a strength increase but a toughness decrease of the fusion and heataffected zones [18]. Tempering processes can be used to increase the toughness at the expense of some strength. When applying post-weld heat treatment, the toughness in the heataffected zone of quenched and tempered high-strength steels can be significantly improved [19].

Microstructural design was used as an efficient method to tailor the microstructural development during the welding process. The microstructure is mainly determined by the chemical composition of the local material and the experienced thermal cycle. A high cooling rate, $t_{8 / 5}$ (cooling time from 800 to $500^{\circ} \mathrm{C}$ ) of 0.6 to $1.3 \mathrm{~s}$ provided a fine-grained microstructure of upper and lower bainite, martensitic islands, polygonal ferrite, and allotriomorphic ferrite [20]. The chemical composition of the weld metal is determined by the base material chemical composition, diffusion processes at high temperatures, and melt movement when reaching liquid state. The chemical composition can be altered by typically used filler wires and by dilution with the base material. For GMAW or SAW, acicular ferrite (AF) often turned out to be a favoured microstructure to obtain high toughness values (e.g. [21-25]). To some extent, bainite, dual-phase structures, and tempered lath martensite showed promising results for limiting cracks [26]. In contrast to bainite, the interlocking microstructure can better retard a crack propagation. Non-metallic inclusions [27] can support the AF formation, e.g. by altering the wire chemistry [28] in combination with the thermal cycles [29]. However, also in single-pass laser-arc hybrid welding of thick high-strength steels, AF was found in optimized welding conditions $[1,30]$.

In addition, for HSS above $960 \mathrm{MPa}$, there are no commercial matching filler wires available [31] that potentially reach the high strength of the base material [32], which are required to provide weld joints with high strengths.

In order to acquire a better understanding of the melt pool movements during welding that can influence the element distribution, high-speed imaging can be used (e.g. [33]). Welding simulations can even give a better insight into the temperature development inside the material (e.g. [34]), which can help to predict the microstructural development that defines the material properties (e.g. $[35,36])$.

Besides the high strength, the toughness of the material is elementary for its application. Toughness can be measured by the Charpy-V-notch $(\mathrm{CVN})$ or by the Crack Tip Opening Displacement (CTOD) method. CVN quickly provides a value of the impact energy, while CTOD provides more information but requires a fatigue pre-crack for controlled crack initiation, which is time-consuming to prepare. A compromise would be desirable, for faster screening of toughness behaviour of different weld metals.

In summary, short-cycle heat treatments as present during NGMLW are not well researched yet. Little experience is available about the impact on the microstructural developments during short-thermal-cycle treatments of laser-based techniques such as NGMLW [37]. The impact on processibility (e.g. crack formation) and the mechanisms of microstructural developments are often unknown. Therefore, this work aims to obtain a better understanding of short-thermal-cycle laser welding and its impact on the microstructural development during multiple short welding cycles and the effect on the resulting weld seam toughness.

\section{Methodology}

\subsection{Materials}

The high-strength steel S1100QL was used as base material for the welding experiments at a thickness of $15.5 \mathrm{~mm}$ and the chemical composition as shown in Table 1.

Due to the quenching and tempering process, the S1100QL steel consist of a tempered-martensitic and bainitic structures with finely distributed carbide precipitates (Fig. 1).

As consumables, the wire material LNM MoNiCr by Lincoln Electric was used (Table 2).

Selected material properties of the base and wire materials are shown in Table 3. The wire properties were identified in standardized all-weld tests. A large gap is filled with multiple layers using GMAW of the wire to avoid material mixing with the base material, while the produced material in the gap is used for mechanical testing.

Based on the LNM MoNiCr wire, material development was conducted adapting the alloy using a variation of the content of the combined elements $\mathrm{Mo}+\mathrm{Ni}+\mathrm{Cr}$. The development resulted in the metal-cored wire $\mathrm{MC} \mathrm{MoNiCr}$ (Table 4).

\subsection{Process setup}

The NGMLW technique was used for the welding experiments. In order to create a defined condition for the experiments, edge preparation was done as shown in Fig. 2c. All sheets were prepared with a flange of $2 \mathrm{~mm}$ height, similar to

Table 1 Chemical composition of S1100QL (wt\%) with balance of Fe

\begin{tabular}{lllllll}
\hline $\mathrm{C}$ & $\mathrm{Si}$ & $\mathrm{Mn}$ & $\mathrm{P}$ & $\mathrm{S}$ & $\mathrm{Al}$ & $\mathrm{Cr}$ \\
0.160 & 0.240 & 1.08 & 0.009 & 0.002 & 0.077 & 0.63 \\
$\mathrm{Mo}$ & $\mathrm{N}$ & $\mathrm{Nb}$ & $\mathrm{Ni}$ & $\mathrm{Ti}$ & $\mathrm{Cu}$ & $\mathrm{B}$ \\
0.600 & 0.0053 & 0.027 & 0.020 & 0.005 & 0.010 & 0.0023 \\
\hline
\end{tabular}




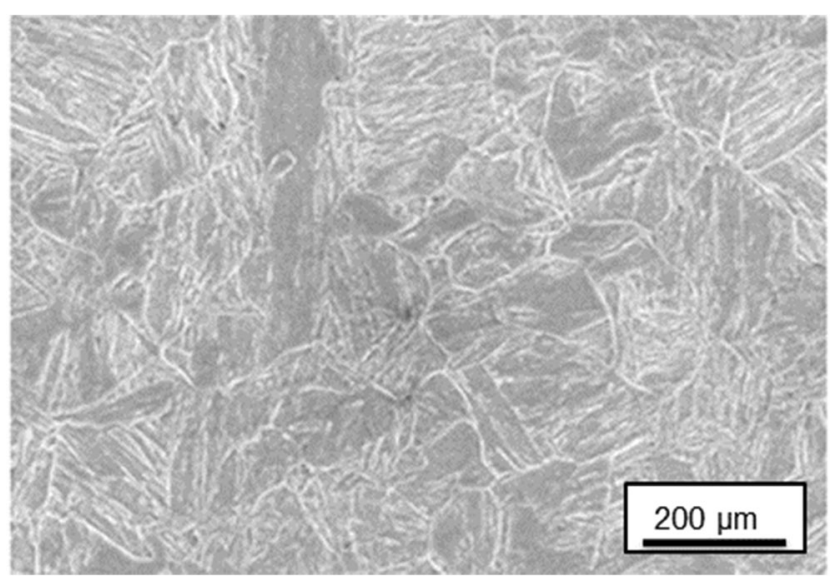

Fig. 1 Microscopic SEM-images showing tempered martensite and bainite structures and distributions of fine carbides in S1100QL

the approach in [1]. This flange was used with the second plate to be joined by an only-laser-process before building the multiple layers in the remaining gap. An IPG fibre laser (max. 15$\mathrm{kW}$ output power, 1070-nm wavelength) was used for the experiments. The laser beam was guided by a fibre with a core diameter of $400 \mu \mathrm{m}$ and focused by a lens optic of $250-\mathrm{mm}$ focal length to a spot diameter of $1.6 \mathrm{~mm}$ on the material surface. The process was done in defocused position at 2.5$\mathrm{m} / \mathrm{min}$ process velocity.

Figure 2 a shows the actual welding setup including the high-speed camera, illumination laser and the wire guide. The wire guide leads the wire into the gap to avoid misalignment of the laser beam and the wire. A wire diameter of $1.2 \mathrm{~mm}$ was used.

Welding was conducted in horizontal direction, always welding in the same direction. In addition, vertical welding was tested leading the wire always from the bottom of the gap to the top (Fig. 2b). The high-speed imaging system was used to record the process zone as illustrated in Fig. 3. A high-speed camera (Fastcam Mini UX100 type 800K-M-16G) in combination with an illumination system (Cavitar, 880 -nm wavelength) was used. The camera was positioned at a low angle of $25^{\circ}$ from the horizontal plane recording the wire and melt pool in the gap at a framerate of $5000 \mathrm{fps}$.

For comparison, GMAW and LAHW were conducted. For GMAW, a DC+ arc type at a current between 208 and $252 \mathrm{~A}$ and a voltage of 24.3 to $27 \mathrm{~V}$ was used. The wire feed was $7.1 \mathrm{~m} / \mathrm{min}$ at a process speed of $0.35 \mathrm{~m} / \mathrm{min}$. For LAHW, a TruDisk 16002 laser with a fibre of $200 \mu \mathrm{m}$ diameter was used guiding the laser beam to the focusing optics (300-mm focal

Table 2 Chemical composition of LNM MoNiCr (wt \%)

\begin{tabular}{lllllll}
\hline $\mathrm{C}$ & $\mathrm{Si}$ & $\mathrm{Mn}$ & $\mathrm{Mo}$ & $\mathrm{Cr}$ & $\mathrm{Ni}$ & $\mathrm{Fe}$ \\
\hline 0.09 & 0.80 & 1.80 & 0.55 & 0.31 & 2.20 & $\mathrm{Bal}$. \\
\hline
\end{tabular}

length). The laser beam focus was positioned $3 \mathrm{~mm}$ below the material surface. Welding in butt joint configuration at $1-\mathrm{m} /$ min process velocity at 8320 -W laser power was performed. The additional arc source fed the wire at $7 \mathrm{~m} / \mathrm{min}$ at a current of $225 \mathrm{~A}$ and a voltage of $21.1 \mathrm{~V}$. The distance between laser and arc was set to $3 \mathrm{~mm}$, while the arc was leading.

Temperature measurements were conducted using thermocouples at several positions (Fig. 4) in order to describe the thermal cycles in the base and weld metal.

\subsection{Process simulation}

\subsubsection{Modelling}

A simulation model was developed to simulate the temperature and melt flow field during NGMLW. The computational fluid dynamic model was implemented in Ansys CFX. Figure 5 a shows the principle sketch of the modelled domain. The used setup represents the experimental setup for validation reasons.

The wire is applied to form the actual track, while the geometry of the melt pool is fixed. Figure $5 \mathrm{~b}$ shows the used mesh showing refinements in the vicinity of the heat source. The heat source is a Gaussian volume heat source. The induced heat is transported by heat conduction inside the material. Simulation parameters are shown in Table 5.

Temperature fields and melt flow fields were extracted from the simulation.

\subsubsection{Model validation}

The model was validated against experimental measurements. Figure 6 a shows that the melt pool dimensions on the surface show good agreement when comparing simulation and experiment.

In addition, the temperature measurements were used to compare the temporal temperature development at the location of the thermocouples. According to Fig. 6b, the temperature development is in good agreement comparing simulation and experiments. This indicates that the model represents the thermal properties of the process.

\subsection{Material testing}

The weld seams were cut perpendicular to the welding direction in order to produce cross sections for the analysis of the microstructure of the weld metal.

Toughness testing was done using a modified Fast-CTOD test. Instead of creating a fatigue crack for the test, electrical discharge machine (EDM) cuts were produced. This method was found to be most suitable to quickly determine the toughness values with acceptable variances. Sample geometries were chosen to be the commonly used geometries for CTOD 
Table 3 Material properties of the used materials

\begin{tabular}{lllll}
\hline Name & Yield strength $(\mathrm{MPa})$ & Tensile strength $(\mathrm{MPa})$ & Elongation at fracture A5 $(\%)$ & Impact energy $(\mathrm{J})$ \\
\hline S1100QL & 1100 & $1200-1500$ & 8 & $40\left(-20{ }^{\circ} \mathrm{C}\right)$ \\
LNM MoNiCr & 895 & 950 & 15 & $70\left(-40{ }^{\circ} \mathrm{C}\right)$ \\
\hline
\end{tabular}

testing. The specimens were all notched in the NP direction (weld seam centre). The cut was a straight path of $1 \mathrm{~mm}$ at the centre of the notch (Fig. 7).

For all tests, the $J$-integral was evaluated according to Eq. 1 for SENB (Single Edge Notched Bend)

$J=2000 \cdot u B \cdot b$

where 2000 is the factor for three point bending, $u$ is the work up to the maximum load (area to the left of the indicated maximum load lines under the recorded load curves), $B$ is the thickness of the specimen, and $b$ is the remaining ligament of the width over the crack (W-a). The $J$-integral is a measure of the crack opening energy. One test per specimen was conducted.

The newly introduced Jprop-integral indicates the energy need during crack propagation. Therefore, the integration was done to evaluate the work from crack initiation (highest load value) to $20 \%$ of the highest load value. For each parameter set, three specimens were evaluated, while the average and the minimum and maximum values were plotted as error bars.

\section{Results}

\subsection{Process observations}

Figure 8 shows a sequence of images of the processing zone recorded by the high-speed camera. It was observed that the process behaviour can significantly vary. While at $0 \mathrm{~ms}$, there is no wetting observed with the sidewall; 5-ms later wetting is achieved. This unstable behaviour was improved by introducing the wire guide for better guidance of the wire.

In addition, the setup conditions of NGMLW lead to a high crack susceptibility. Therefore, pre-heating was used for the experiments to decrease the cooling rate and thereby thermal distortion.

Table 4 Chemical composition of the newly developed $\mathrm{MC} \mathrm{MoNiCr}$ (wt\%)

\begin{tabular}{llllll}
\hline $\mathrm{C}$ & $\mathrm{Si}$ & $\mathrm{Mn}$ & $\mathrm{Cr}+\mathrm{Ni}+\mathrm{Mo}$ & $\mathrm{Ti}+\mathrm{Nb}+\mathrm{V}$ & $\mathrm{Fe}$ \\
\hline 0.1 & 0.65 & 1.70 & 3.0 & 0.05 & Bal.
\end{tabular}

The thermal cycles at NGMLW at horizontal and vertical welding process modifications indicate that the vertical welding technique shows a lower temperature drop between the single welding cycles (Fig. 9). Therefore, the subsequent weld seam was produced at a higher base material temperature.

\subsection{Microstructure}

The microstructure of S1100QL base material mainly consists of martensite. With an additional tempering process, the crystal lattice has the possibility to relax with the effect that the strength decreases, while toughness increases, so that a material with a satisfactory combination of tensile and toughness properties can be produced. Therefore, the base material structure of Q\&T steels consisting of a tempered-martensitic and bainitic structure with finely distributed carbide precipitates

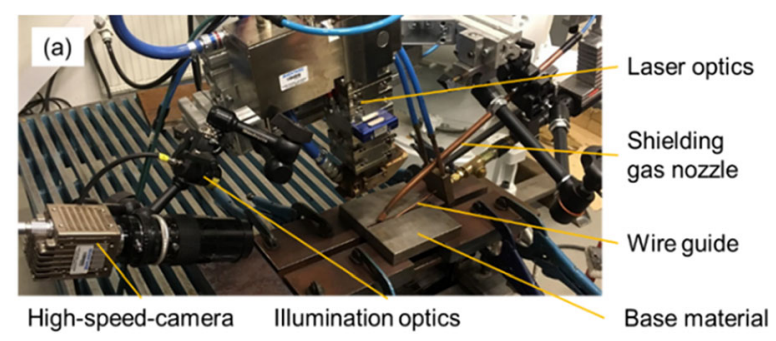

(b)
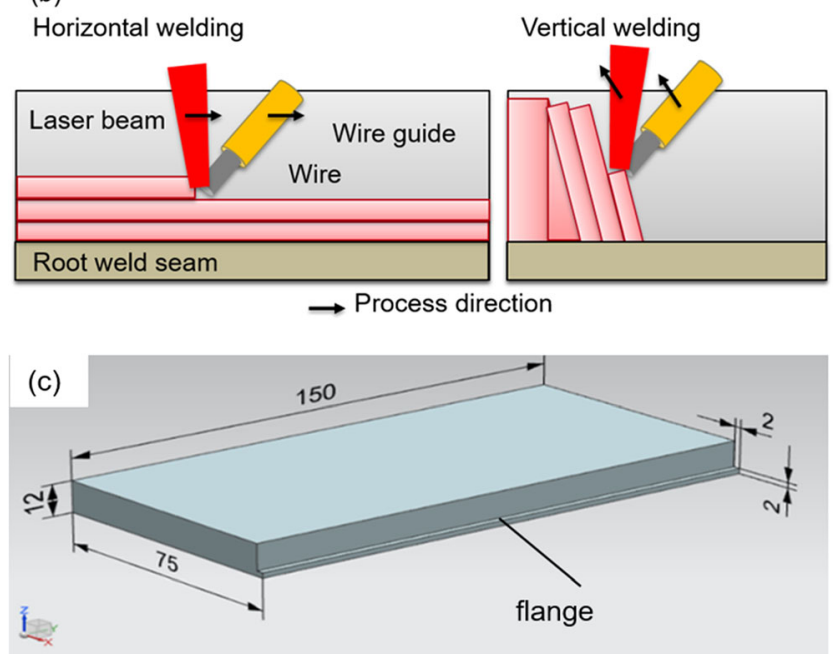

Fig. 2 a Welding setup. b Sketch of the process variants. c Specimen geometry 


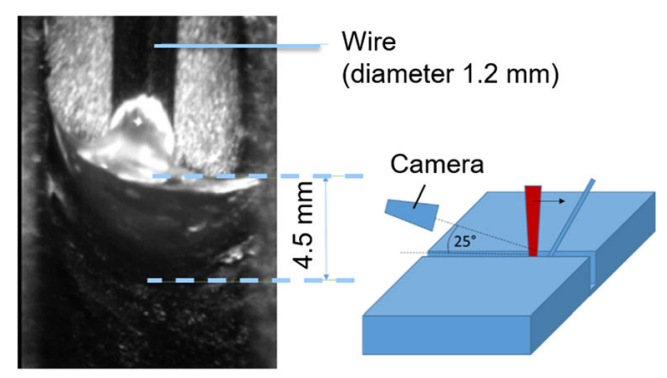

Fig. 3 High-speed image of the process and observation setup
(Fig. 10a) is aimed for during the quenching and tempering process.

The weld metal of the GMAW weld metal (Fig. 10b) shows a solidification structure with parts of martensite, while in LAHW (Fig. 10c), the microstructure of the base material reveals a tempered-martensitic and bainitic structure.

During NGMLW (Fig. 10d, e), coalesced bainite dominate the microstructure. In addition, carbon-rich martensitic islands were identified appearing in the HAZ in the overlapping area of the single weld seams. A few nonmetallic inclusions are visible. Small ferrite regions were

(a)
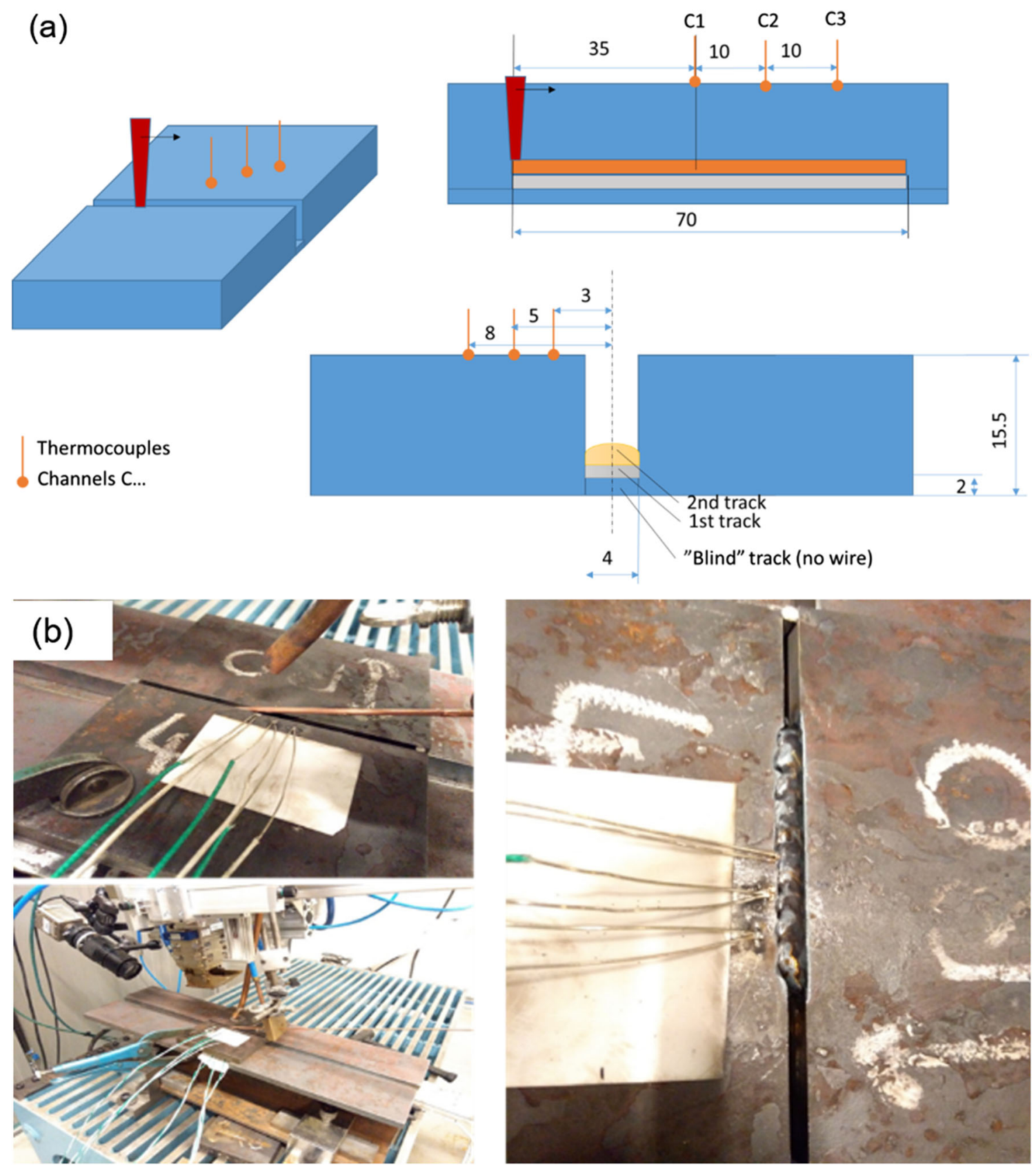

Fig. 4 a Sketch of the locations of the thermocouples and $\mathbf{b}$ temperature measurement setup 
Fig. 5 a Sketch of the simulation approach (cross-sectional view, dimensions in $\mathrm{mm}$ and (b) mesh used for the NGMLW model with fine mesh in the processing zone (3D view and view into the gap)
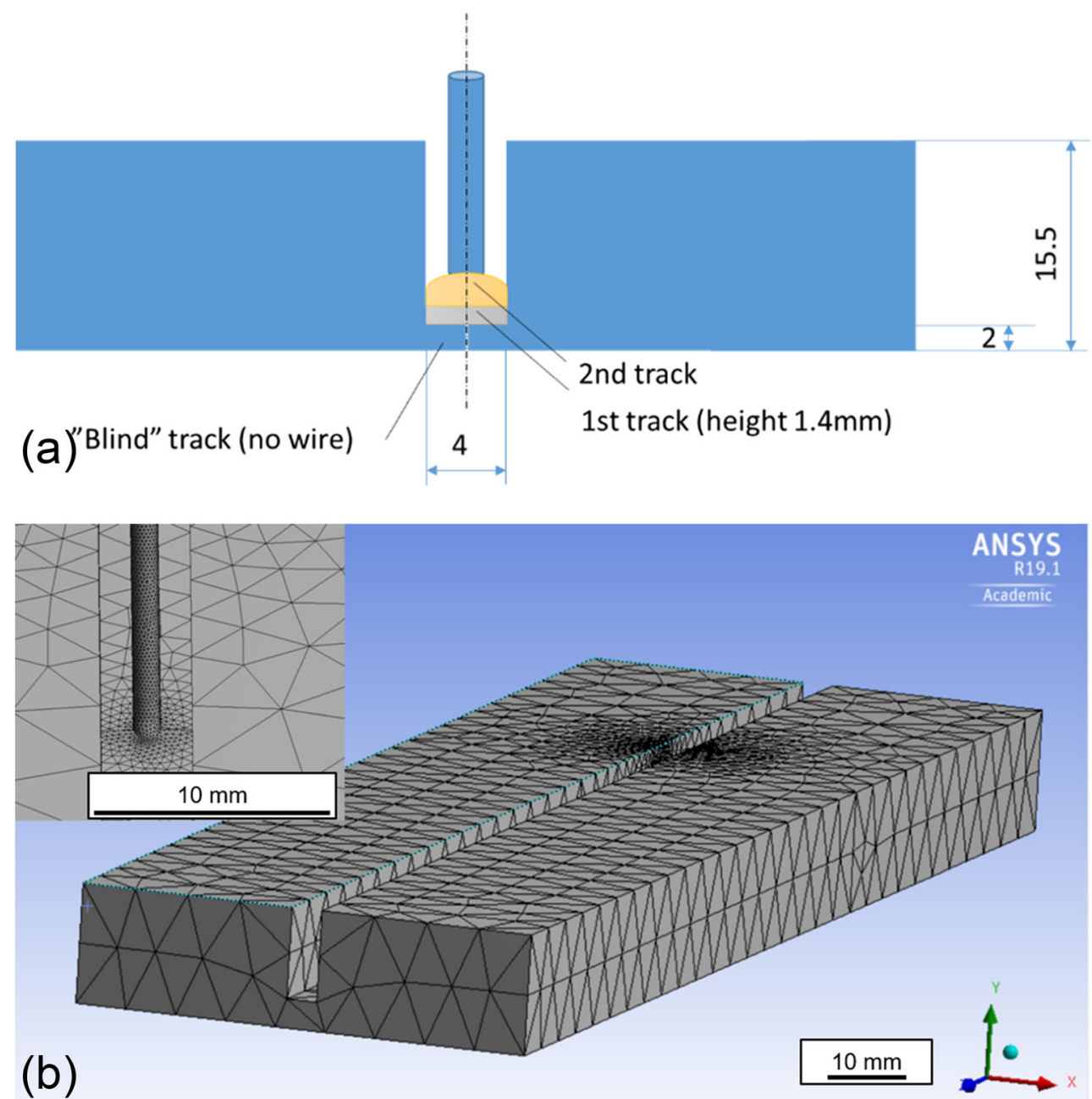

found within the bainitic structure and Widmanstätten ferrite appears at the grain boundaries. Figure $10 \mathrm{f}$ shows an example of the typical grain growth during solidification.

In addition, the Ni-content was evaluated at different positions of the weld seam (Fig. 11). It was seen that the Nicontent was high ( $>1.2$ mass $\%$ ) in all depths of the weld seam, which indicates a good mixing.

Table 5 Summary of the simulation parameters

\begin{tabular}{lll}
\hline & Value & Unit \\
\hline Process speed & $0.3 / 0.6$ & $\mathrm{~m} / \mathrm{min}$ \\
Laser power & 3000 & $\mathrm{~W}$ \\
Laser spot diameter & 1.6 & $\mathrm{~mm}$ \\
Material & Steel & - \\
Beam profile & Gaussian & - \\
Time steps & $0.001-0.1$ (variable) & $\mathrm{s}$ \\
\hline
\end{tabular}

\subsection{Simulation results}

The simulation results of the temperature field of the second layer (Fig. 12) show that the induced heat leads to a melting of the weld seam but also to a heat treatment of the structure below.

The simulation was also conducted in a higher layer (layer $10)$ in order to identify potential differences and tendencies (Fig. 13). However, the dimensions of the temperature fields in the different layers are comparable. A slight geometrical dimension decrease of the melt pool is visible in layer 10 , which can be explained by the missing heat accumulation at the bottom of the specimen in lower layers. The analysis shows that layers are completely re-melted when adding the subsequent layer and partially melt when applying the following one. Afterwards, the layer is heated up above $800{ }^{\circ} \mathrm{C}$ up to three times. This indicates that tempering effects of the already processed structure can occur during the welding of the layers.

From the simulation of the temperature field, the characteristic cooling time $t_{8 / 5}$ was determined on the material surface (Fig. 14). 


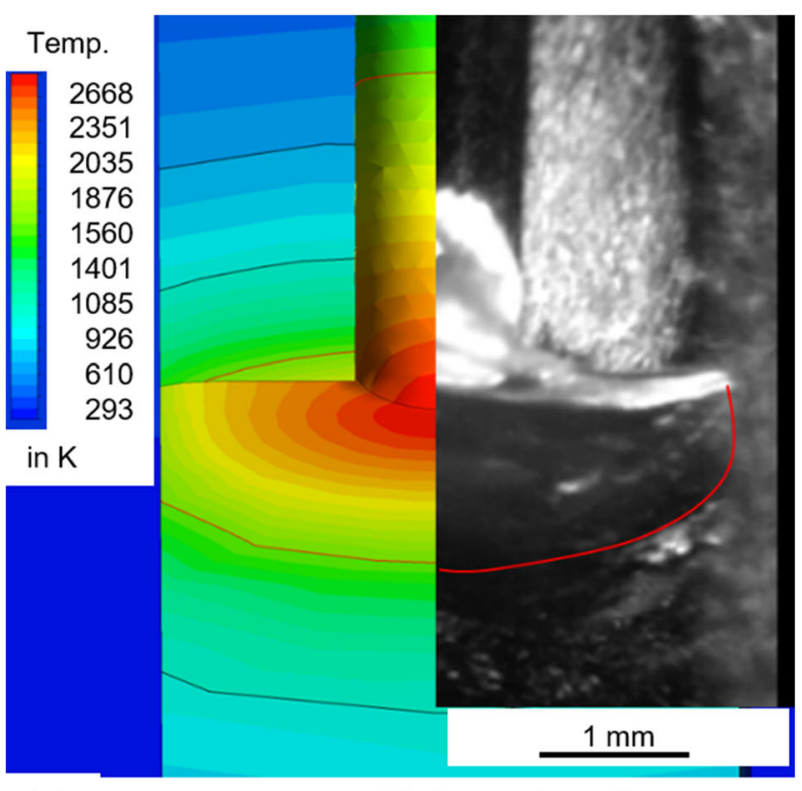

(a)

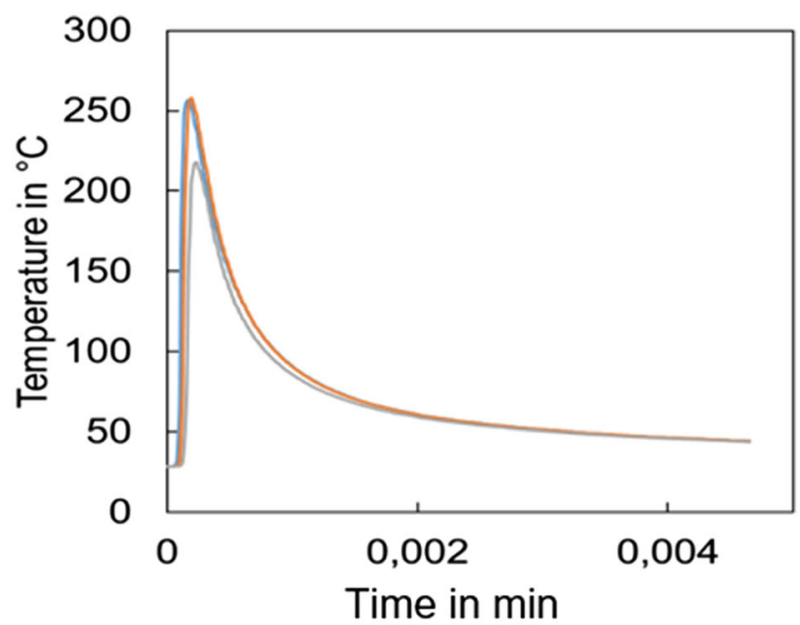

(b)

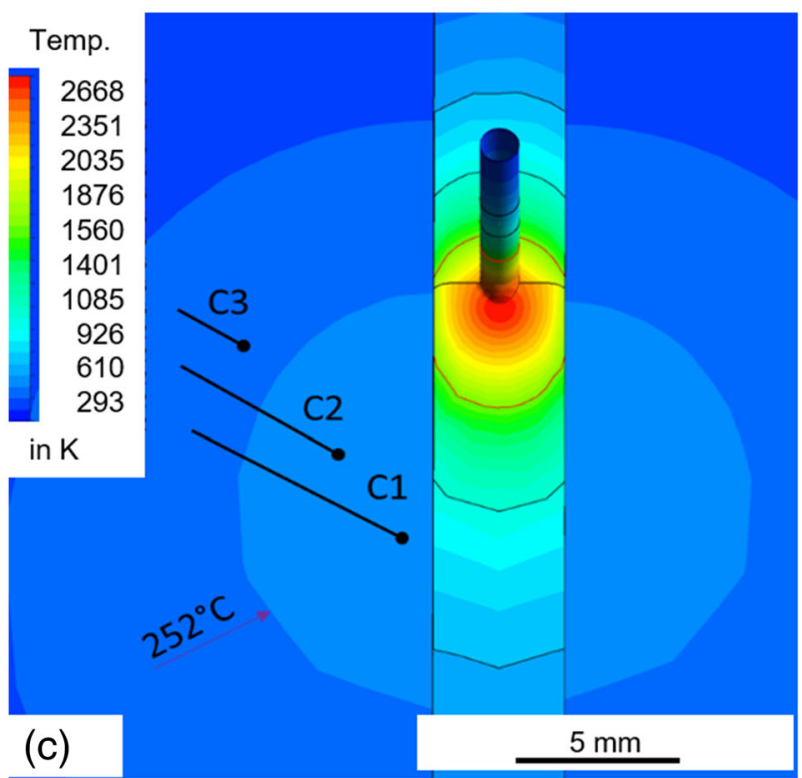

Fig. 6 a Melt pool size validation of the simplified CFD model compared with a high-speed image. b Exemplary measurement of the temperature during NGMLW using thermocouples and $\mathbf{c}$ simulation results

In addition, the melt flow was evaluated in order to analyse the wire material distribution inside the melt pool. The simulation results (Fig. 15) show that an upwards melt flow in the base material melt pool is created. This indicates that the additional material from the wire remains in the upper part of the welded joint, and limited mixing with the base material/ previous layers seems to be possible.

\subsection{Toughness testing}

The toughness tests ( $J$-integral and the $J$ prop-integral, Fig. 16) show that the NGMLW strategy is able to produce toughness values above the GMAW method and almost reaches the LAHW values.

The highest toughness values of the NGMLW are reached when using the core-wire $\mathrm{MC} \mathrm{MoNiCr}$ at horizontal welding.

\section{Discussion}

High-strength steel welding was examined by investigating the impacts of the chemical composition of the wire in combination with different thermal treatments by different welding procedures. During the wire development, chemical elements were systematically varied. It was seen that the wire

(a)
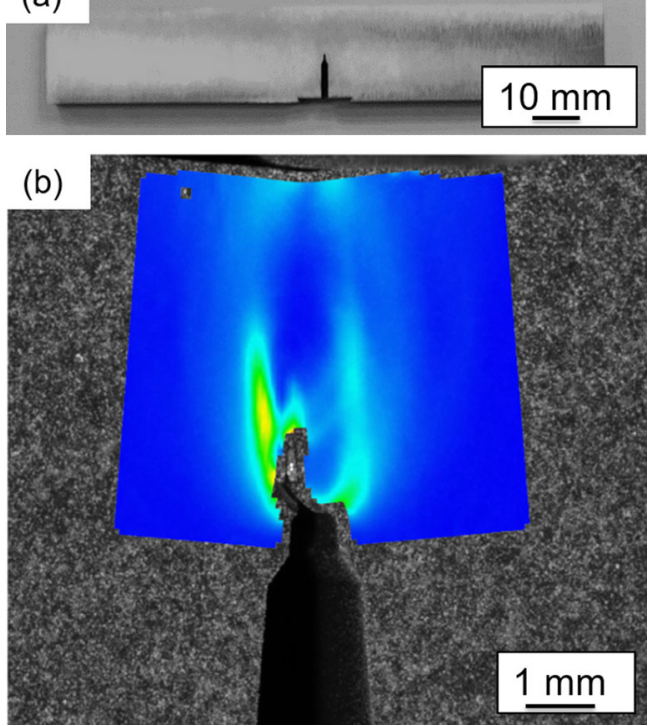

Fig. 7 a Sample for modified toughness testing with EDM cut. b VonMises strain field during crack propagation for CTOD specimen with precrack 
Fig. 8 Sequence of high-speed frames showing the varying wetting behaviour of the melt pool on the base material (horizontal welding)

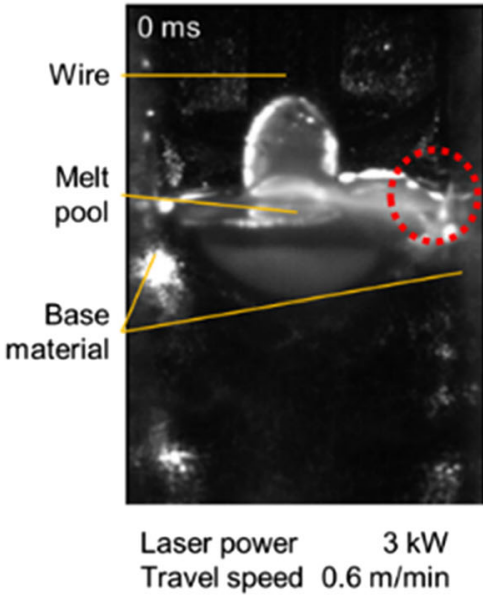

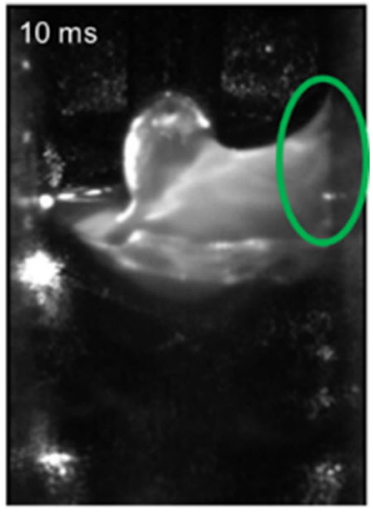

$\because:$ Lack of wetting Wetting material shows conditions where high strength and toughness values were achieved. Therefore, the research question is to explain the conditions that are necessary to achieve high strength and toughness and which influencing factors must be considered during welding processes.

\subsection{Modified chemical composition}

It could be observed that the modifications of the wire chemistry to the new alloy $\mathrm{MC} \mathrm{MoNiCr}$ can lead to high toughness values (Fig. 16b), reaching values comparable to LAHW
Fig. 9 Thermal cycles recorded by thermocouples on the bottom of the base material at a horizontal and b vertical NGMLW (a)

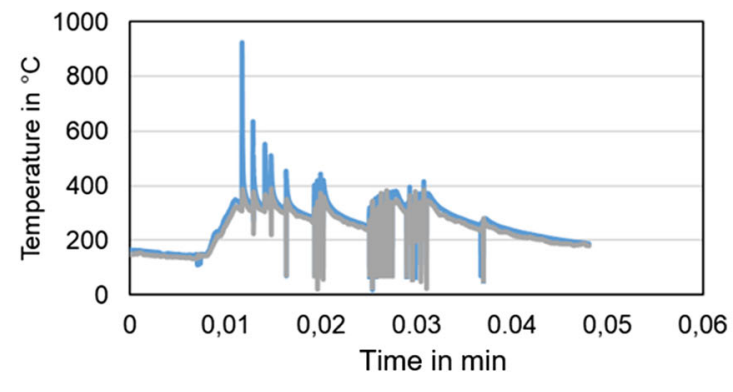

$-0 \mathrm{~mm}-10 \mathrm{~mm}$

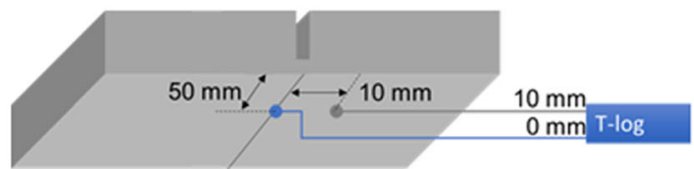

(b)

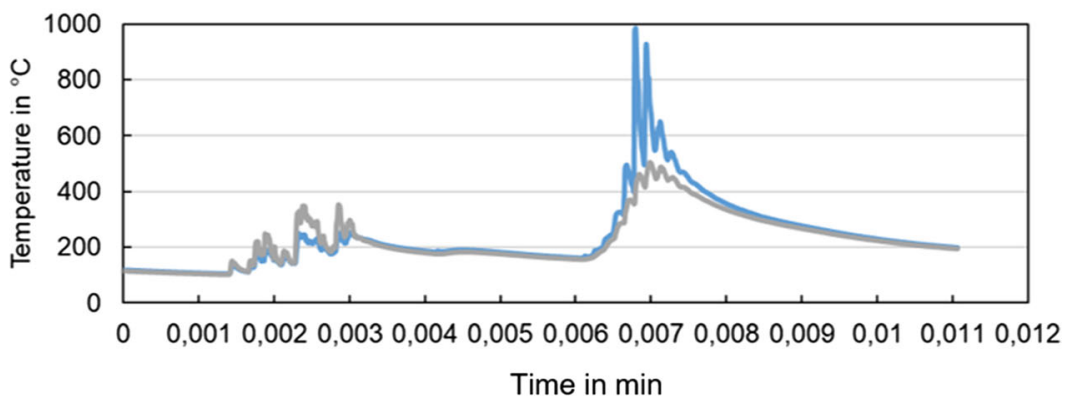

$-0 \mathrm{~mm}-10 \mathrm{~mm}$ 
Fig. 10 Microstructures of different welding techniques. a Base material. b GMAW (LNM MoNiCr). c LAHW (LNM MoNiCr). d NGMLW (h, MC MoNiCr). e NGMLW (v, LNM MoNiCr). f NGMLW (h, LNM $\mathrm{MoNiCr}$ )

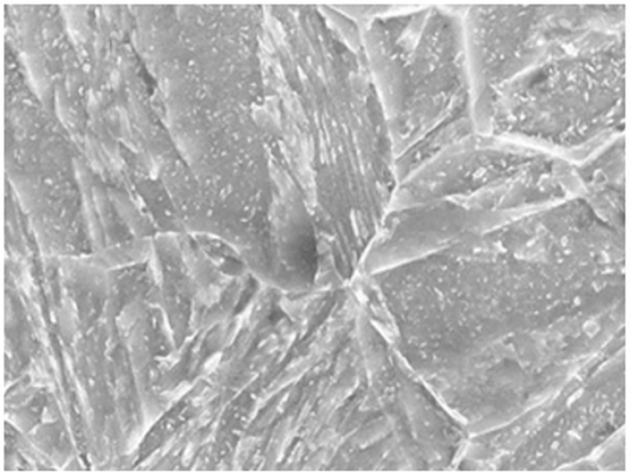

a)

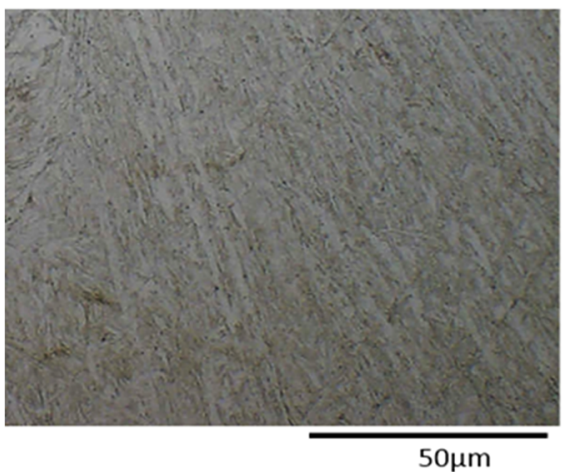

c)

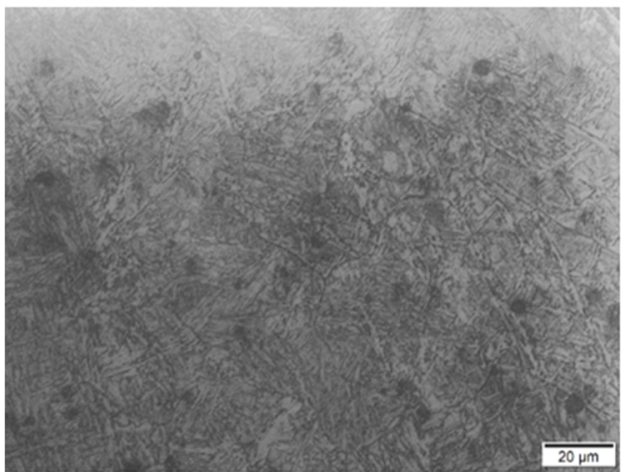

e)

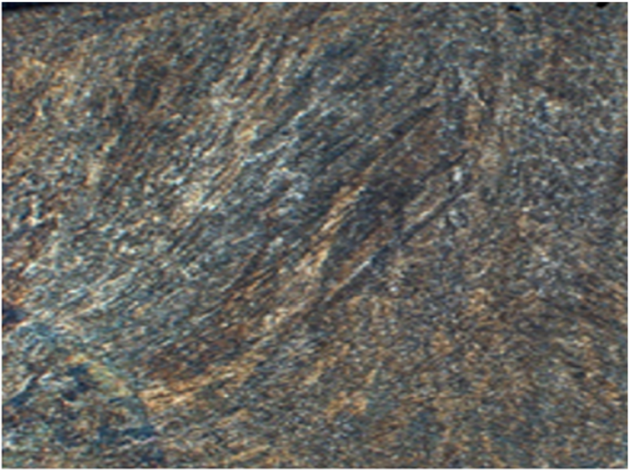

b)

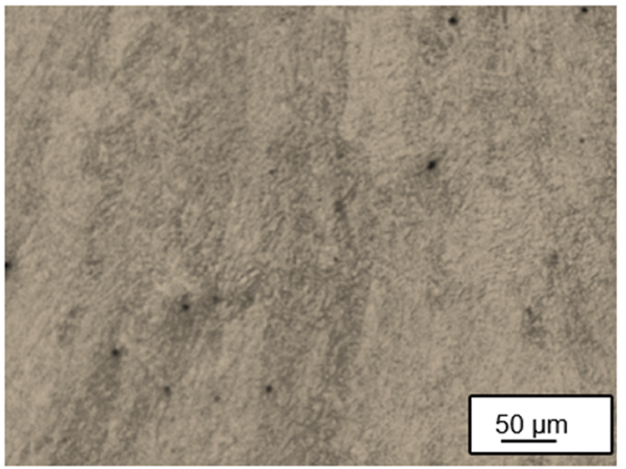

d)

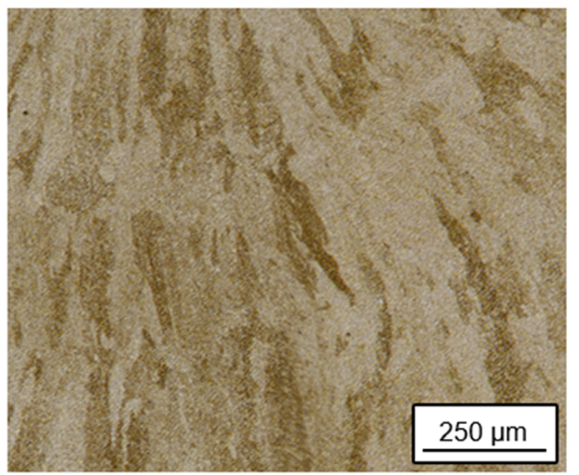

f)

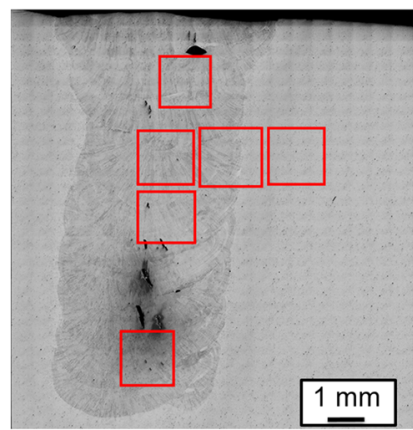

\begin{tabular}{|l|l|l|}
\hline \multicolumn{3}{|c|}{ Ni-content in mass-\% } \\
\hline 1.21 & & \\
\hline 1.43 & 0.22 & 0 \\
\hline 1.77 & & \\
\hline 1.24 & & \\
\hline
\end{tabular}

Laser power

Travel speed Wire feed rate Pre-heating temp.

Weld start temp. Direction

Fig. 11 EBSD evaluation of the Ni-content within a welded seam of NGMLW methods. A possible explanation for this effect is that the developed metal-cored $\mathrm{MC}$ MoNiCr wire showed promising microstructures (Fig. 10d). Interlocking structures were found showing bainite islands within the martensite, indicating a high strength at high toughness. However, the joint showed some defects, perhaps due to inadequate shielding of the melt pool. Therefore, the toughness increase during crack initiation ( $J$-integral, Fig. 16a) could not be visible in the material tests.

In order to form the desired microstructure, the chemical composition in the weld metal should be well distributed. Limited mixing of the filler wire chemical elements in the melt pool was identified to be a main influencing factor on the toughness behaviour due to the inhomogeneous material 
Fig. 12 Cross section of a simulation of the temperature fields when welding layer 2

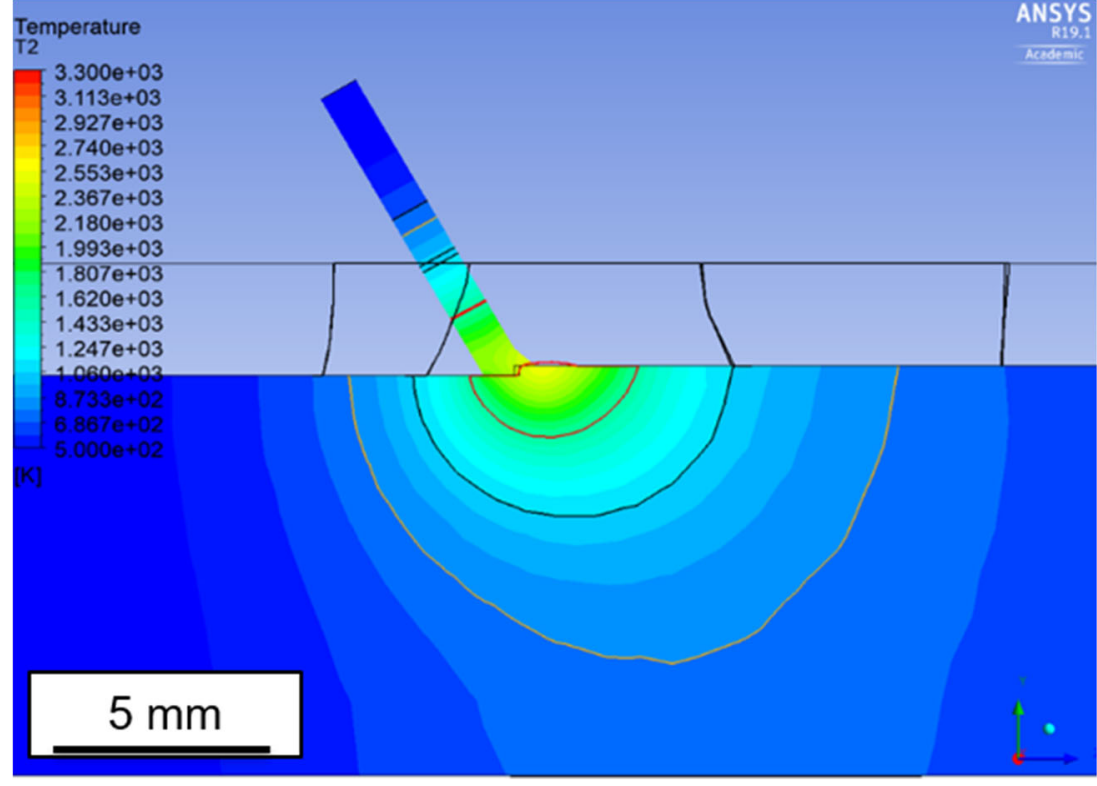

properties. Since the local chemical composition depends on melt pool mixing and diffusion processes, both mechanisms can lead to local variations of elements in the weld-metal and heat-affected zone of welded joints.

In NGMLW simulations, it was found that the melt pool movement indicates a limited material mixing. However, due to the comparably small height of the single weld seams (Fig. 4) and the comparably large re-melting of the structure below (Fig. 15), the element mixing can lead to a good distribution of the wire material in the weld metal (Fig. 11) compared with, e.g., typical LAHW or GMAW joints that can show no wire mixing in the lower parts of the weld seam. Although the Nicontent slightly varies in the measured zones, the desired microstructural development was achieved. This is the basis for achieving a microstructure that can lead to a high toughness. This is also valid for thick sheet welding. Conventional welding methods often need special edge preparation in order to achieve a homogeneous element distribution throughout the whole weld seam. NGMLW has the advantage to guarantee the mixing due to the process strategy of applying thin weld seams layer by layer.

\subsection{Thermal treatment}

Different welding techniques were applied in the study in order to compare the impact of different thermal treatments of the material on the resulting microstructures and toughness properties.

Compared with conventional welding techniques, the laser-based processes LAHW and NGMLW show significantly shorter cooling times $t_{8 / 5}$ (Table 6).
Fig. 13 Simulation results of the 10th layer showing the

temperature fields from a side view (longitudinal cross section through the centre of the joint)

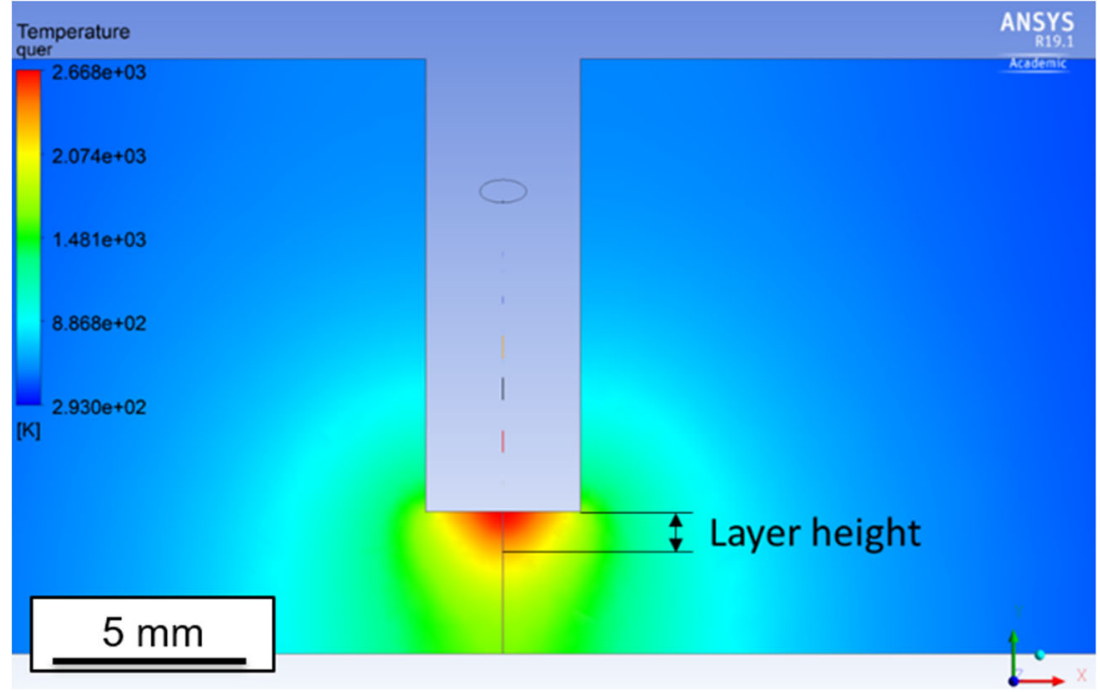


Fig. 14 Thermal simulation of the NGMLW with lines indicating the melt pool (red line), $800^{\circ} \mathrm{C}$ (blue line) and $500{ }^{\circ} \mathrm{C}$ (black line) isotherms

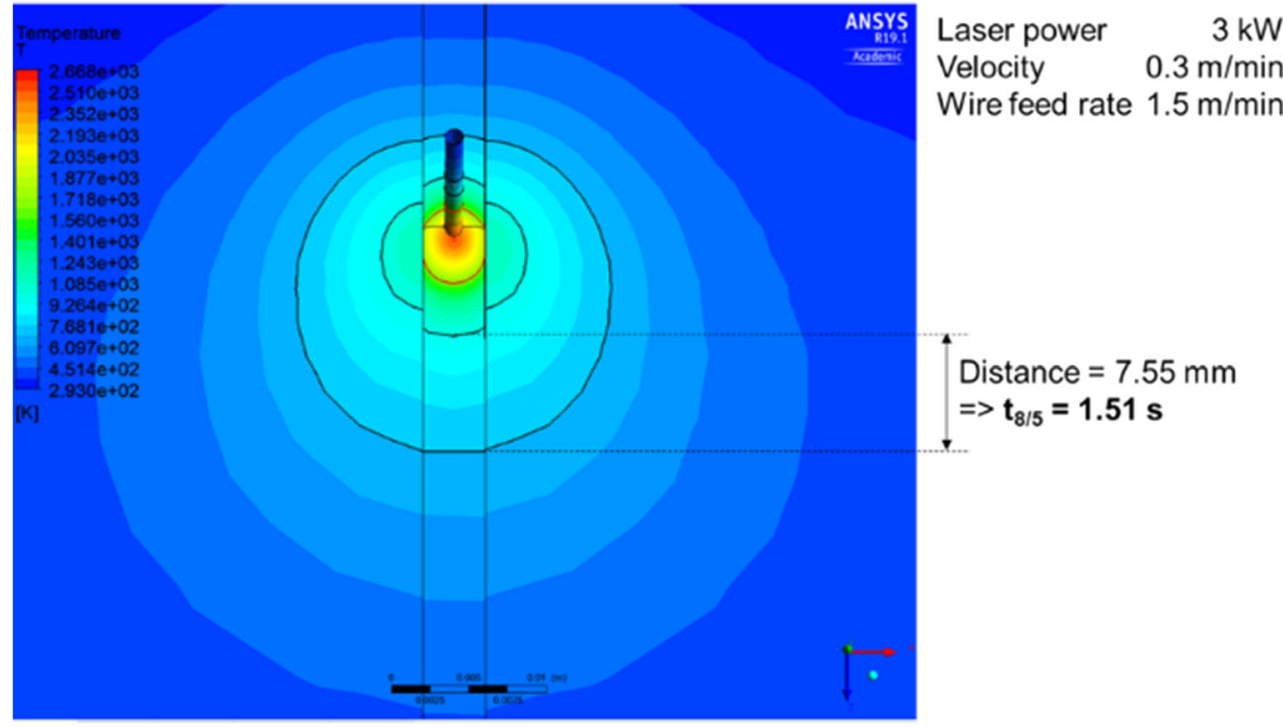

A low cooling time of $t_{8 / 5}=1.51 \mathrm{~s}$ (horizontal welding) was extracted for NGMLW (Fig. 14). A short cooling time is expected to lead to a fully martensitic transition according to, e.g., Zheng et al. [38], a high strength and low toughness. However, in NGMLW, the short cooling times of the weld metal is followed by additional heating cycles when applying subsequent layers. Therefore, a tempering process can be induced (Fig. 9) that can soften the material and can lead to the observed high toughness values (Fig. 16).

Vertical welding shows even shorter thermal cycles for each applied layer. In addition, higher 'pre-heating' temperatures must be expected for the subsequent weld seam, which can support the microstructural changes leading to higher toughness. According to the results of this work, the vertical welding increases the crack-initiation toughness value ( $J$-integral, Fig. 16$)$. However, the geometry of the vertical weld seams might be a disadvantage against crack propagation (Jprop-integral, Fig. 16).

During NGMLW, the short thermal cycles should have led to fully martensitic transformation of the weld metal (e.g. [38]). However, only small islands of martensite were found in a bainitic structure. This indicates
Fig. 15 Melt flow visualization from the CFD simulation of layer 2 showing flow directions upwards in the base material

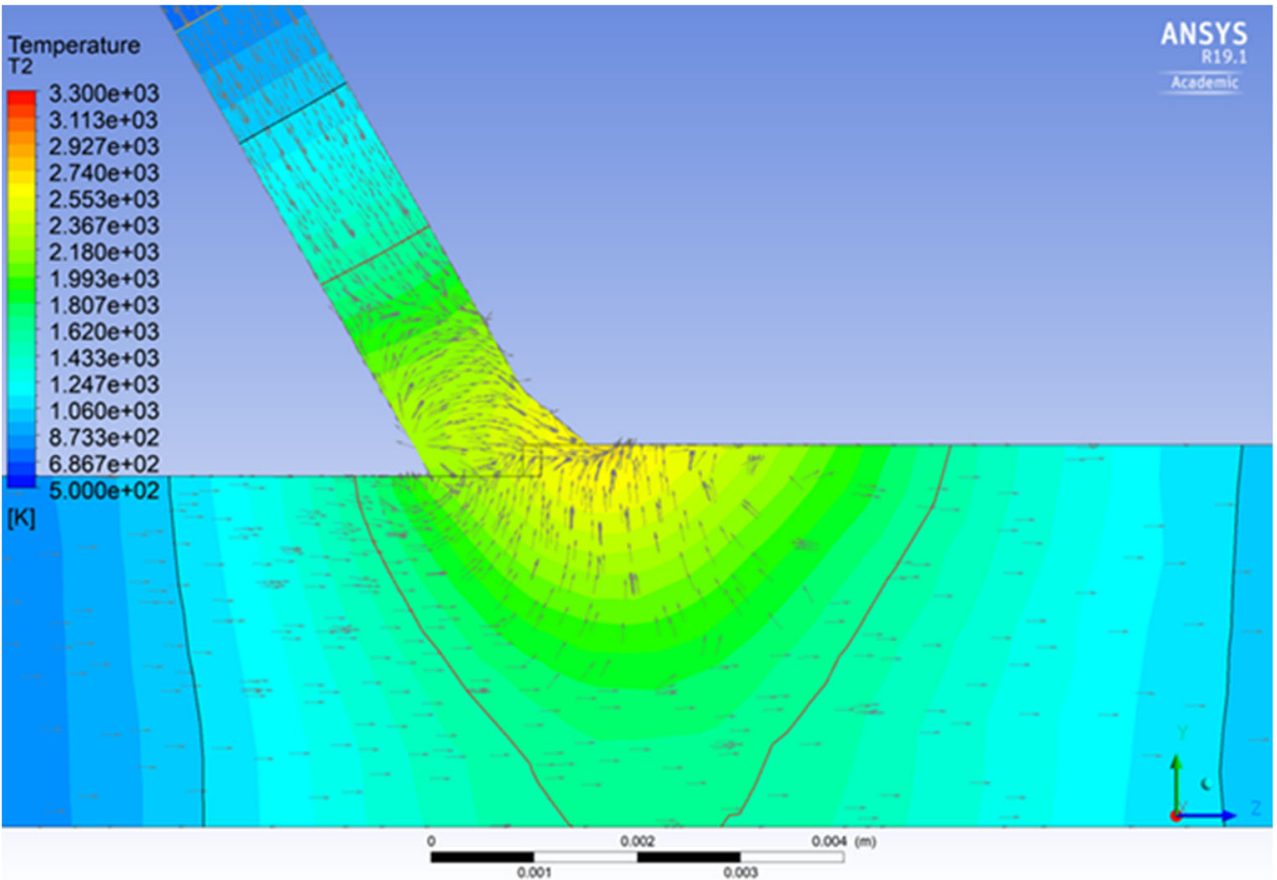




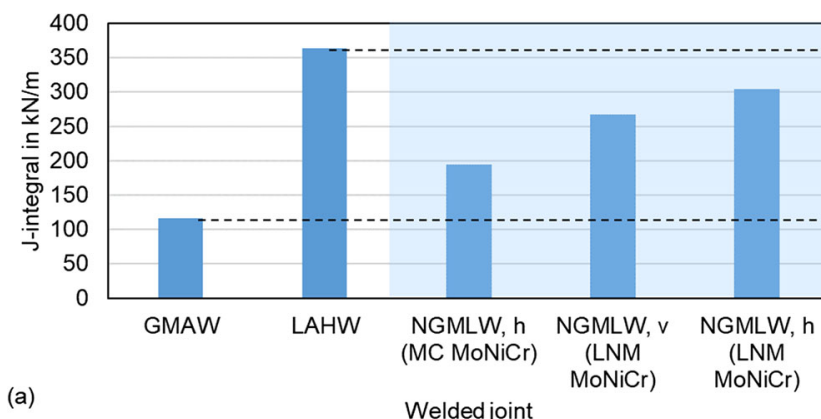

(a)

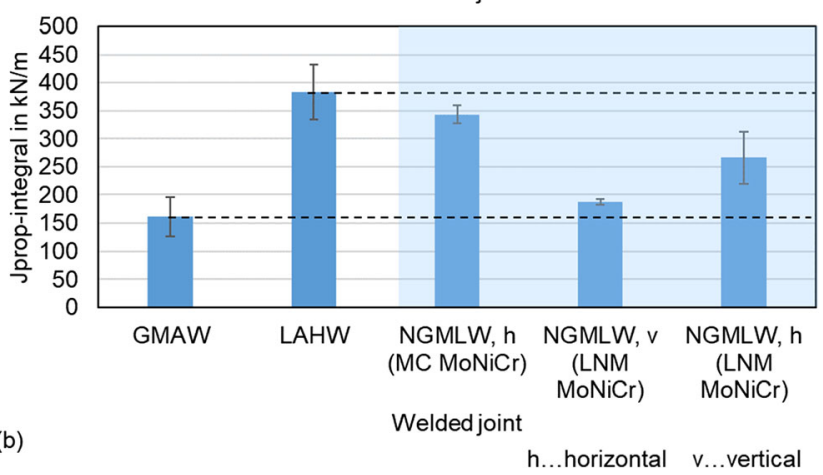

Fig. 16 Toughness measurements at different welding strategies and wire materials evaluating a the $J$-integral and $\mathbf{b}$ the $J$ prop-integral

that the diffusion time was not long enough for the carbon to homogeneously distribute. Even ferrite islands are still present in the structure. The identified nonmetallic inclusions [39] give hints that interlocking structures were formed. However, the number of inclusions might have been too small (below 10 to $26 \%$ [40]) to form acicular ferrite (AF). The high cooling rates during NGMLW might be hindering the AF formation. At 20 to $30 \mathrm{~K} / \mathrm{s}$, the transformation to mainly AF was achieved [41, 42], while even higher AF fractions were present at two-stage cooling [42]. LAHW still shows higher toughness values due to the overall longer cooling times (Fig. 16).

Multiple thermal treatments of the weld metal in combination with optimum homogeneously distributed chemical compositions can lead to weld metal showing high strength at high toughness.

Table 6 Estimations of cooling times $t_{8 / 5}$ in the weld metal for different welding methods at typical parameter setting (estimated using simplified Rykalin equations)

\begin{tabular}{ll}
\hline Welding method & Cooling time $t_{8 / 5}$ in $\mathrm{s}$ \\
\hline GMAW [7] & 9 \\
LAHW & 1 to 5 \\
SAW [8] & 15 \\
\hline
\end{tabular}

\section{Conclusions}

1) The results of the fast toughness testing method show that high toughness values can be achieved at high strength. This effect can be related to the microstructural changes of the weld metal induced by using modified filler wire material and adapted processing strategies.

2) The increased weld-metal toughness is likely related to the re-transformation and tempering when welding subsequent layers.

3) The measured high toughness values at NGMLW were concluded to originate from the occurrence of interlocking microstructures that form due to the short thermal cycles applied that lead to microstructures with tempered martensite and bainitic. The short heat cycles during vertical welding could not show advantages in toughness, which is assumed to derive from the geometrical weakness of the weld seam in the horizontal direction.

Acknowledgements Open access funding provided by Lulea University of Technology.

Funding The authors gratefully acknowledge funding from the EC Research Fund for Coal and Steel, RFCS, for the project OptoSteel, no. 709954, and SteelS4EV, no. 800726, and from Vinnova SIP Production 2030 project 2019-0078, ACCEL.

Open Access This article is licensed under a Creative Commons Attribution 4.0 International License, which permits use, sharing, adaptation, distribution and reproduction in any medium or format, as long as you give appropriate credit to the original author(s) and the source, provide a link to the Creative Commons licence, and indicate if changes were made. The images or other third party material in this article are included in the article's Creative Commons licence, unless indicated otherwise in a credit line to the material. If material is not included in the article's Creative Commons licence and your intended use is not permitted by statutory regulation or exceeds the permitted use, you will need to obtain permission directly from the copyright holder. To view a copy of this licence, visit http://creativecommons.org/licenses/by/4.0/.

\section{References}

1. Cao X, Wanjara P, Huang J, Munro C, Nolting A (2011) Hybrid fiber laser-arc welding of thick section high strength low alloy steel. Mater Des 32(6):3399-3413

2. Miki C, Homma K, Tominaga T (2002) High strength and high performance steels and their use in bridge structures. J Constr Steel Res 58(1):3-20

3. Wang W, Shan Y, Yang K (2009) Study of high strength pipeline steels with different microstructures. Mater Sci Eng A 502:38-44

4. Zhao M-C, Shan Y-Y, Xiao FR, Yang K, Li YH (2002) Investigation on the H2 S-resistant behaviors of acicular ferrite and ultrafine ferrite. Mater Lett 57:141-145

5. Onoro J, Ranninger C (1997) Fatigue behaviour of laser welds of high strength low-alloy steels. J Mater Process Technol 68:68-70 
6. Chao YJ, Ward JD Jr, Sands RG (2007) Charpy impact energy, fracture toughness and ductile-brittle transition temperature of dual-phase 590 Steel. Mater Des 28(2):551-557

7. Zhang W, Kim CH, DebRoy T (2004) Heat and fluid flow in complex joints during gas metal arc welding - part II: application to fillet welding of mild steel. J Appl Phys 95(9):5220-5229

8. Moeinifar S, Kokabi AH, Hosseini HM (2011) Role of tandem submerged arc welding thermal cycles on properties of the heat affected zone in X80 microalloyed pipe line steel. J Mater Process Technol 211(3):368-375

9. Piekarska W, Kubiak M, Bokota A (2011) Numerical simulation of thermal phenomena and phase transformations in laser-arc hybrid welded joints. Arch Metall Mater 56(2):409-421

10. Li B, Li ZY, Xiong JG, Xing L, Wang D, Li Y (2006) Laser welding of $\mathrm{Zr} 45 \mathrm{Cu} 48 \mathrm{Al} 7$ bulk glassy alloy. J Alloys Compd 413(1-2):118-121

11. Petring, D., Fuhrmann, C., Wolf, N., \& Poprawe, R. (2007). Progress in laser-MAG hybrid welding of high-strength steels up to $30 \mathrm{~mm}$ thickness. In International Congress on Applications of Lasers \& Electro-Optics (Vol. 2007, No. 1, p. 604). Laser Institute of America

12. Engström, H., Nilsson, K., Flinkfeldt, J., Nilsson, T., Skirfors, A., \& Gustavsson, B. (2001). Laser hybrid welding of high strength steels. In International Congress on of Lasers \& Electro-Optics (Vol. 2001, No. 1, pp. 125-134). Laser Institute of America

13. Milewski JO, Sklar E (1998) "Narrow gap laser welding," Google patent US5760365 A

14. Zhang X, Ashida E, Tarasawa S, Anma Y, Okada M, Katayama S, Mizutani M (2011) Welding of thick stainless steel plates up to $50 \mathrm{~mm}$ with high brightness lasers. J Laser Appl 23:022002

15. Elmesalamy A, Francis J, Li L (2014) A comparison of residual stresses in multi pass narrow gap laser welds and gas-tungsten arc welds in AISI 316L stainless steel. Int J Pressure Vessels Piping 113:49-59

16. Dittrich D, Schedewy R, Brenner B, Standfuß J (2013) Laser-multipass narrow-gap-welding of hot crack sensitive thick aluminum plates. Phys Procedia 41:225-233

17. Shi H, Zhang K, Xu Z, Huang T, Fan L, Bao W (2014) Applying statistical models optimize the process of multi-pass narrow-gap laser welding with filler wire. Int J Adv Manuf Technol 75:279-291

18. Guo W, Li L, Crowther D, Dong S, Francis JA, Thompson A (2016) Laser welding of high strength steels (S960 and S700) with medium thickness. J Laser Appl 28(2):022425

19. Gáspár M, Sisodia R (2018) Improving the HAZ toughness of Q+ T high strength steels by post weld heat treatment. In: IOP Conference Series: Materials Science and Engineering, vol 426, p 012012

20. Lee J, Pan Y (1995) The formation of intragranular acicular ferrite in simulated heat-affected zone. ISIJ Int 35:1027-1033

21. Bhadeshia HKDH, Keehan E, Karlsson L, Andrén H-O (2006) Coalesced bainite. Trans Indian Institute of Metals 59:689-694

22. Bhadeshia H, Honeycombe R (2006) Steels: microstructure and properties. Elsevier Ltd.

23. Thewlis G (2004) Materials perspective: classification and quantification of microstructures in steels. Mat Sci Techn 20:143-160

24. Lambert-Perlade A, Gourgues AF (2004) A. Pineau: Austenite to bainite phase transformation in the heat-affected zone of a high strength low alloy steel. Acta Materialia 52:2337-2348

25. Kitahara H, Ueiji R, Tsuji N, Minamino Y (2006) Crystallographic feature of lath martensite in low-carbon steel. Acta Mater 54:1279_ 1288
26. Koo JY, Luton MJ, Bangaru NV, Petkovic RA, Fairchild DP, Petersen CW et al (2004) Metallurgical design of ultra highstrength steels for gas pipelines. International Journal of Offshore and Polar Engineering 14(01)

27. Loder D, Michelic SK, Bernhard C (2017) Acicular ferrite formation and its influencing factors-a review. J Mater Sci Res 6:24-43

28. Fattahi M, Nabhani N, Hosseini M, Arabian N, Rahimi E (2013) Effect of Ti-containing inclusions on the nucleation of acicular ferrite and mechanical properties of multipass weld metals. Micron. 45:107-114

29. Zhang D, Terasaki H, Komizo Y (2010) In-situ observation of the formation of intragranular acicular ferrite at non-metallic inclusions in C-Mn steel. Acta Mater 58:1369-1378

30. Roepke C, Liu S (2009) Hybrid laser arc welding of HY-80 steel. Weld J

31. Jorge JCF, Faragasso SM, Guimarães de Souza L et al (2015) Effect of post-welding heat treatment on the mechanical and microstructural properties of extra high-strength steel weld metals, for application on mooring equipment. Weld Int 29(7):521-529

32. Umekuni A, Masubuchi K (1997) Usefulness of undermatched welds for high-strength steels. Welding Journal-Including Welding Research Supplement 76(7):256s

33. Eriksson, I., J. Powell, A. F. H. Kaplan: Measurements of fluid flow inside laser welding keyholes, Sci. Techn. Weld. Join., v 16, n 7, pp 636-641 (2011)

34. Paul A, Debroy T (1988) Free surface flow and heat transfer in conduction mode laser welding. Metall Trans B 19(6):851-858

35. Otto A, Koch H, Leitz KH, Schmidt M (2011) Numerical simulations-a versatile approach for better understanding dynamics in laser material processing. Phys Procedia 12:11-20

36. De A, Walsh CA, Maiti SK, Bhadeshia HKDH (2003) Prediction of cooling rate and microstructure in laser spot welds. Sci Technol Weld Join 8(6):391-399

37. Li R, Wang T, Wang C, Yan F, Shao X, Hu X, Li J (2014) A study of narrow gap laser welding for thick plates using the multi-layer and multi-pass method. Opt Laser Technol 64:172-183

38. Zheng S, Wu Q, Huang Q, Liu S, Han Y (2011) Influence of different cooling rates on the microstructure of the HAZ and welding CCT diagram of CLAM steel. Fusion Engineering and Design 86(9-11):2616-2619

39. Jung JG, Kim J, Noh KM, Park KK, Lee YK (2012) Effects of B on microstructure and hardenability of resistance seam welded HSLA linepipe steel. Sci Technol Weld Join 17:77-84

40. Kang Y, Jang J, Park J, Lee C (2014) Influence of Ti on nonmetallic inclusion formation and acicular ferrite. Metal Mater Int 20:119-127

41. Loder D, Michelic S (2016) Systematic investigation of acicular ferrite formation on laboratory scale. Mater Sci Technol 33:162171

42. Moeinifar S, Kokabi A, Hosseini H (2011) Effect of tandem submerged arc welding process and parameters of Gleeble simulator thermal cycles on properties of the intercritically reheated heat affected zone. Mater Des 32:869-876

Publisher's note Springer Nature remains neutral with regard to jurisdictional claims in published maps and institutional affiliations. 